\title{
Eleven to Fifteen Years
}

National Cancer Institute

\section{Source}

National Cancer Institute. Eleven to Fifteen Years. NCI Thesaurus. Code C148659.

An indication that something has lasted, or occurred during, 11 to 15 years. 